EHLERT, P.A.D., LUZ, J.M.Q., INNECCO, R. Propagação vegetativa da alfavaca-cravo utilizando diferentes tipos de estacas e substratos. Horticultura Brasileira, Brasília, v.22, n1, p. 10-13, jan-mar 2004.

\title{
Propagação vegetativa da alfavaca-cravo utilizando diferentes tipos de estacas e substratos ${ }^{1}$
}

\author{
Polyana Aparecida D. Ehlert' ${ }^{1}$; José Magno Q. Luz ${ }^{2}$; Renato Innecco ${ }^{3}$ \\ ${ }^{1}$ UNESP-FCA-Dept ${ }^{\circ}$ Horticultura, C. Postal 237, 18603-970 Botucatu-SP; E-mail: polyehlert@yahoo.com.br; ${ }^{2}$ UFU-ICIAG, C. Postal \\ 593, 38400-902 Uberlândia-MG; ${ }^{3}$ UFC-Dept ${ }^{0}$ Fitotecnia, C. Postal 12.168, 60356-001 Fortaleza-CE.
}

\section{RESUMO}

A propagação vegetativa é considerada importante ferramenta para o melhoramento de espécies lenhosas e herbáceas e vem sendo amplamente utilizada, visando melhorar e manter variedades de importância econômica e medicinal. Neste contexto utilizou-se estacas de alfavaca-cravo de $15 \mathrm{~cm}$ para apicais e $25 \mathrm{~cm}$ para as medianas, sendo estas com e sem folhas. As estacas foram plantadas em bandejas de isopor de 72 células, utilizando-se 10 substratos. Após 35 dias, as estacas foram retiradas com cuidado, sendo as partes aéreas e radiculares separadas e acondicionadas em saco de papel e mantidas em estufa a $70^{\circ} \mathrm{C}$ por $48 \mathrm{~h}$ para posterior avaliação da matéria seca. Analisou-se a percentagem de enraizamento, número de folhas na estaca, peso de matéria seca de folha e de raiz. Não houve interação significativa entre os diferentes tipos de substrato e estaca para percentagem de enraizamento, sendo que os substratos de modo geral diferiram pouco entre si. Entre os tipos de estaca destacaram-se para esta variável a mediana sem folha e a apical com folha. Para as demais variáveis houve interação significativa entre o tipo de estaca e o substrato. A melhor estaca foi a mediana sem folhas plantadas em substrato arisco + esterco + húmus e vermiculita nas seguintes proporções: 20\%:40\%:40\%; 40\%:20\%:40\% e 40\%:40\%.

Palavras-chave: Ocimum gratissimum L., mudas, planta medicinal.

\begin{abstract}
Vegetative propagation of the wild basil using different types of cuttings and substrata

The vegetative propagation is an important tool for the improvement of woody and herbaceous species and could be an important tool to improve and to maintain varieties of economic and medicinal importance. In this experiment cuttings $15 \mathrm{~cm}$ long of the apical portion and also $25 \mathrm{~cm}$ long cuttings of the medial portion of the stems, were used both with and without leaves. The cuttings were planted on styrofoam trays with 72 cells, using 10 different substrata. After 35 days, cuttings were carefully removed, the aerial portion being separated from the roots and conditioned in paper bags and maintained in a stove at $70^{\circ} \mathrm{C}$ for $48 \mathrm{~h}$, for the dry weight evaluation. There were analyzed the percentage of rooting, number of leaves per cutting and leaf and root dry weight. There was no interaction among substrata and cuttings for the percentage of rooting. Were no significant differences in the rooting among the different substrata used in the experiment there. Better rooting was observed on cuttings from the medial portion of the stem without leaves and from the apical portion with leaves. For the other variables there was significant interaction between the cuttings and the substrata. The cutting that presented best results were those from the medial portion without leaves in the substrata with $\mathrm{A}+\mathrm{E}$ sandy soil + humus + vermiculite in the following proportions: (20\%: 40\%:40\%); (40\%:20\%:40\%) and (40\%:40\%:20\%) respectively.
\end{abstract}

Keywords: Ocimum gratissimum L., seedlings, medicinal plant.

\section{(Recebido para publicação em 29 de novembro de 2002 e aceito em 18 de setembro de 2003)}

\begin{abstract}
A alfavaca-cravo (Ocimum gratissimum L.) pertence à família Labiatae, originária da Ásia e África (Correa Júnior, 1994; Matos, 1998), apresentando-se como perene nessas regiões; em regiões frias é anual. É planta alógama e seu melhoramento pode ser difícil devido ao tamanho da flor e de suas características reprodutivas. A propagação vegetativa pode ser a solução para a manutenção e multiplicação dessa espécie.

Hibrida-se facilmente, apresentando grande número de subespécies e variedades (Correia Júnior, 1994). Muitas espécies de plantas cultivadas, tanto
\end{abstract}

lenhosas como herbáceas, são altamente heterozigotas; portanto, a propagação vegetativa é ferramenta importante para o melhoramento dessas culturas, devido à eficiência e rapidez na fixação de genótipos com características desejáveis e formação de clones superiores (Hartmann et al., 1990).

Estudos promovidos no Brasil e no exterior demonstraram que a utilização, no plantio, de estacas herbáceas, semilenhosas e lenhosas, com folha presente ou ausente, assim como a época de coleta delas, influenciam consideravelmente no enraizamento (Bezerra e Lederman, 1995). Browse (1979) rela- ta que estacas semilenhosas são mais espessas e possuem melhores condições de sobrevivência que as herbáceas, por apresentarem elevadas quantidades de assimilados e, por isso podem produzir raízes sob condições de fraca luminosidade. Morales (1990), trabalhando com enraizamento de citrus, verificou que a presença de folhas nas estacas elevou a percentagem de estacas enraizadas. Zancan (1989), utilizou estaca semilenhosa de ameixeira para plantio. Verificou elevada percentagem de enraizamento nas estacas retiradas da porção apical dos ramos devido ser a região de síntese de auxina. Outro im-

${ }^{1}$ Parte da dissertação apresentada à Universidade Federal do Ceará pela primeira autora, para obtenção do título de mestre em agronomia, área de concentração em fitotecnia. 
Tabela 1. Percentagem média de enraizamento de diferentes tipos de estacas de alfavaca-cravo (O. gratissimum L. ), em diferentes combinações de substrato. Pentecoste (CE), UFC-FEVC, 1999.

\begin{tabular}{|c|c|c|c|c|c|}
\hline \multirow{2}{*}{ Substratos $^{1}$} & \multicolumn{4}{|c|}{ Tipos de estacas $^{2}$} & \multirow{2}{*}{$\begin{array}{l}\text { Médias de } \\
\text { substratos' }\end{array}$} \\
\hline & EMCF & EMSF & EACF & EASF & \\
\hline$A+E 100 \%+H 0 \%+V 0 \%$ & $62,04 a$ & $75,00 a$ & $69,94 a$ & $63,84 a$ & 67,8 b \\
\hline$A+E 80 \%+H 20 \%+V 0 \%$ & $100,00 a$ & $100,00 a$ & $98,05 a b$ & $73,37 \mathrm{~b}$ & $97,1 \mathrm{a}$ \\
\hline$A+E 60 \%+H 40 \%+V 0 \%$ & $100,00 a$ & $100,00 a$ & $100,00 a$ & $75,00 a$ & $98,3 a$ \\
\hline$A+E 20 \%+H 80 \%+V 0 \%$ & $50,83 b$ & $100,00 a$ & $93,30 a b$ & $98,05 a$ & $91,5 a b$ \\
\hline$A+E 60 \%+H 20 \%+V 20 \%$ & $98,05 a$ & $100,00 a$ & $100,00 a$ & $50,00 \mathrm{~b}$ & $94,7 a$ \\
\hline$A+E 40 \%+H 40 \%+V 20 \%$ & $100,00 a$ & $100,00 a$ & $100,00 a$ & $93,30 a$ & $99,5 a$ \\
\hline$A+E 0 \%+H 80 \%+V 20 \%$ & $100,00 a$ & $100,00 a$ & $95,85 a$ & $98,05 a$ & $99,3 a$ \\
\hline$A+E 40 \%+H 20 \%+V 40 \%$ & $92,34 a$ & $100,00 a$ & $100,00 \mathrm{a}$ & $95,85 a$ & $97,6 a$ \\
\hline$A+E 20 \%+H 40 \%+V 40 \%$ & $100,00 \mathrm{a}$ & $100,00 a$ & $100,00 a$ & $95,85 a$ & $99,7 a$ \\
\hline$A+E 0 \%+H 20 \%+V 80 \%$ & $84,69 a$ & $100,00 a$ & $100,00 \mathrm{a}$ & $92,34 a$ & $97,1 \mathrm{a}$ \\
\hline Médias de Estacas** & $94,3 \mathrm{BC}$ & $99,7 \mathrm{~A}$ & $98,6 \mathrm{AB}$ & $86,7 \mathrm{C}$ & \\
\hline
\end{tabular}

$1 / \mathrm{A}+\mathrm{E}=$ arisco + esterco; $\mathrm{H}=$ húmus; $\mathrm{V}=$ vermiculita; ${ }^{2} / \mathrm{EDMCF}=$ estaca mediana com folha; $\mathrm{EMSF}=$ estaca mediana sem folha; $\mathrm{EACF}=\mathrm{estaca}$ apical com folha; $E A S F=$ estaca apical sem folha.

*/**Médias seguidas por letras minúsculas distintas na vertical e maiúscula na horizontal diferem entre si pelo teste Tukey a $5 \%$ de probalidade.

portante fator para um bom enraizamento é o substrato. Segundo Couvillon (1988), o substrato pode ser determinante para o sucesso do enraizamento de estacas, embora para algumas espécies vegetais, e mesmo cultivares, não haja efeito de substrato (Pokorny e Austin, 1982).

No que se refere ao uso de estaquia com plantas medicinais pouco se sabe. Mendonça (1997), trabalhando com alecrim-pimenta (Lippia sidoides Cham.) sob sombrite constatou que o melhor tipo de estaca foi a herbácea com a presença de folhas.

Neste trabalho procurou-se determinar o melhor tipo de estaca e substrato para a propagação vegetativa da alfavaca-cravo.

\section{MATERIAL E MÉTODOS}

Estacas semilenhosas de plantas de alfavaca-cravo (O. gratissimum L.) cultivadas no horto de plantas medicinal da Fazenda Experimental Vale do Curu foram retiradas de plantas propagadas sexualmente, com aproximadamente 2,5 anos de idade. Obteve-se estacas das porções apical (com $15 \mathrm{~cm}$ ) e mediana (com $25 \mathrm{~cm}$ ), sem folhas e com um par de folhas alternadas. Estas foram plantadas em bandejas de isopor de 72 células, utilizando-se três substratos (ester- co bovino curtido, húmus e vermiculita) em diferentes concentrações, complementadas para $100 \%$ com arisco (que corresponde ao terriço na região sudeste) num total de 10 combinações (tabela 1) $\mathrm{O}$ delineamento foi inteiramente casualizado, em esquema fatorial (10x4), em três repetições com seis estacas por parcela, num total de 720 estacas. Posteriormente foram levadas para sombrite com $50 \%$ de cobertura e com nebulização intermitente. Aos 35 dias após a instalação do experimento, as estacas foram cuidadosamente retiradas das bandejas para evitar danos da parte aérea e sistema radicular. Em seguida, separaram-se as partes aéreas do sistema radicular, que foram acondicionadas separadamente em sacos de papel e levadas para estufa à temperatura de $70^{\circ} \mathrm{C}$ por 48 horas. Avaliou-se a percentagem de enraizamento; número de folhas nas estacas (realizadas logo após as estacas serem retiradas das bandejas); peso da matéria seca de folha e peso da matéria seca de raiz.

\section{RESULTADOS E DISCUSSÃO}

Verificou-se elevada taxa de sobrevivência das estacas, apesar de nem todas apresentarem raiz. Não houve interação significativa entre os diferentes substratos e tipos de estaca. O substrato que continha $100 \%$ de arisco + esterco foi o que proporcionou menor enraizamento, com percentagem média de 67,8\% (Tabela 1). Com relação aos tipos de estacas, as mais altas porcentagens de enraizamentos ocorreram nas medianas sem folhas e nas apicais com folhas $(99,7 \%$ e $98,6 \%$, respectivamente). Trabalhando com citrus, Morales (1990) verificou maior enraizamento quando utilizou estacas com folhas. A não diferença significativa entre estacas medianas sem folhas e estacas apicais com folhas, contraria o encontrado por Zancan (1989), que pesquisando sobre ameixeira, obteve melhores respostas com estacas da porção apical dos ramos, sendo provável que as diferenças encontradas sejam devido às diferenças existentes entre as espécies trabalhadas.

Para o número de folhas nas estacas, peso de matéria seca de folhas e de raiz verificou-se que houve interação significativa entre tipo de estaca e substrato. Para a primeira característica, de maneira geral, a estaca mediana sem folha destacou-se, pois foi a única que apresentou superioridade em relação às outras estacas, dentro de todas as combinações dos substratos (Tabela 2). Por outro lado, com relação aos substratos, a estaca mediana sem folha apresentou as maiores variações do número de folhas e o substrato que se 
Tabela 2. Número de folhas em diferentes tipos de estacas de alfavaca-cravo (O.gratissimum L.), em diferentes combinações de substrato. Pentecoste, (CE), UFC-FEVC, 1999.

\begin{tabular}{|c|c|c|c|c|c|c|}
\hline \multirow{3}{*}{$\frac{\text { Substratos }^{1}}{\mathrm{~A}+\mathrm{E} 100 \%+\mathrm{H} 0 \%+\mathrm{V} 0 \%}$} & \multicolumn{6}{|c|}{ Tipos de estacas $^{2}$} \\
\hline & \multirow{2}{*}{$\begin{array}{c}\text { EMCF } \\
50,7 a b A B\end{array}$} & \multicolumn{2}{|l|}{ EMSF } & \multicolumn{2}{|c|}{ EACF } & \multirow{2}{*}{$\begin{array}{c}\text { EASF } \\
29,7 \text { a B }\end{array}$} \\
\hline & & 83,0 & $A$ & $41,7 \quad b c$ & B & \\
\hline$A+E 80 \%+H 20 \%+V 0 \%$ & $90,7 a \quad A$ & $116,7 a b c$ & $A$ & $114,3 a$ & A & 42,3 a $B$ \\
\hline$A+E 60 \%+H 40 \%+V 0 \%$ & $84,0 a b \mathrm{~A}$ & $85,3 \quad b c$ & A & $85,3 a b$ & A & 24,3 a $B$ \\
\hline$A+E 20 \%+H 80 \%+V 0 \%$ & $84,3 a b \mathrm{~A}$ & 74,7 & $A$ & 66,3 bc & A & 29,3 a $B$ \\
\hline$A+E 60 \%+H 20 \%+V 2 \%$ & 78,3ab A & 94,7 bc & A & $71,7 a b$ & A & 30,7 a $B$ \\
\hline$A+E 40 \%+H 40 \%+V 20 \%$ & $79,3 a b \mathrm{~A}$ & $106,7 a b c$ & A & $86,3 a b$ & A & 17,3 a $B$ \\
\hline$A+E 0 \%+H 80 \%+V 20 \%$ & $69,3 a b A B$ & $92,0 \quad b c$ & A & 21,7 & C & 37,7 a $B C$ \\
\hline$A+E 40 \%+H 20 \%+V 40 \%$ & $85,7 a b \quad B$ & $129,0 a b$ & A & $52,0 \quad b c$ & B & 53,3 a $B$ \\
\hline$A+E 20 \%+H 40 \%+V 40 \%$ & $75,0 a b \quad B$ & $151,0 a$ & $A$ & 59,7 & $\mathrm{BC}$ & 31,3 a $\quad C$ \\
\hline$A+E 0 \%+H 20 \%+V 80 \%$ & 41,0 b A & 39,7 & A & $45,0 \quad b c$ & A & 30,7 a $A$ \\
\hline
\end{tabular}

${ }^{1 / \mathrm{A}+\mathrm{E}}=$ arisco + esterco; $\mathrm{H}=$ húmus $; \mathrm{V}=$ vermiculita; ${ }^{2} \mathrm{EMCF}=$ estaca mediana com folha; $\mathrm{EMSF}=$ estaca mediana sem folha; $\mathrm{EACF}=\mathrm{estaca}$ apical com folha; EASF=estaca apical sem folha.

Médias seguidas por letras distintas minúsculas na vertical e maiúscula na horizontal, diferem entre si a 5\% de probabilidade pelo teste Tukey.

Tabela 3. Médias do peso de matéria seca (g) de folha em diferentes tipos de estacas de alfavaca-cravo (O. gratissimum L.), em diferentes combinações de substrato. Pentecoste, (CE), UFC-FEVC, 1999.

\begin{tabular}{|c|c|c|c|c|c|c|c|}
\hline \multirow{3}{*}{$\frac{\text { Substratos }^{1}}{A+E 100 \%+H 0 \%+V 0 \%}$} & \multicolumn{7}{|c|}{ Tipos de estacas $^{2}$} \\
\hline & \multicolumn{2}{|l|}{ EMCF } & \multicolumn{2}{|l|}{ EMSF } & EACF & \multicolumn{2}{|c|}{ EASF } \\
\hline & $0,19 \mathrm{~cd}$ & $A B$ & 0,34 & $A$ & $0,15 \mathrm{bc} A B$ & $0,08 \mathrm{a}$ & $B$ \\
\hline$A+E 80 \%+H 20 \%+V 0 \%$ & $0,48 a$ & A & $0,59 \mathrm{bcd}$ & A & $0,44 a \quad A$ & $0,13 a$ & B \\
\hline$A+E 60 \%+H 40 \%+V 0 \%$ & $0,35 a b c$ & $A$ & 0,42 cde & $A$ & $0,36 a b \quad A$ & $0,09 a$ & B \\
\hline$A+E 20 \%+H 80 \%+V 0 \%$ & $0,38 \mathrm{abcd}$ & $A$ & 0,39 cde & A & $0,31 a b c A$ & $0,08 a$ & B \\
\hline$A+E 60 \%+H 20 \%+V 20 \%$ & $0,40 a b$ & $A B$ & $0,56 \mathrm{bcd}$ & A & $0,29 a b c \quad B C$ & $0,09 a$ & C \\
\hline$A+E 40 \%+H 40 \%+V 20 \%$ & $0,46 a b$ & $A B$ & $0,61 \mathrm{bc}$ & A & $0,35 a b$ & $0,05 a$ & C \\
\hline$A+E 0 \%+H 80 \%+V 20 \%$ & $0,26 \mathrm{bcd}$ & $B$ & $0,56 \mathrm{bcd}$ & A & $0,06 \quad C \quad B$ & 0,16 a & B \\
\hline$A+E 40 \%+H 20 \%+V 40 \%$ & $0,39 a b$ & B & $0,69 a b$ & A & $0,17 \quad b c$ & 0,16 a & C \\
\hline$A+E 20 \%+H 40 \%+V 40 \%$ & $0,31 \mathrm{ab}$ & B & $0,89 a$ & A & 0,26 bc $B C$ & $0,09 a$ & C \\
\hline$A+E 0 \%+H 20 \%+V 80 \%$ & 0,16 & A & 0,21 & A & 0,17 bc A & 0,11 a $A$ & \\
\hline
\end{tabular}

${ }_{1 / \mathrm{A}+\mathrm{E}}=$ arisco + esterco $\mathrm{H}=$ húmus; $\mathrm{V}=$ vermiculita $;{ }^{2} \mathrm{EMCF}=$ estaca mediana com folha; $\mathrm{EMSF}=$ estaca mediana sem folha; $\mathrm{EACF}=\mathrm{estaca}$ apical com folha; EASF=estaca apical sem folha.

Médias seguidas por letras distintas minúsculas na vertical e maiúscula na horizontal, diferem entre si a 5\% de probabilidade pelo teste de Tukey.

destacou foi o que tinha $20 \%$ de arisco + esterco, $40 \%$ de vermiculita e $40 \%$ de húmus, porém não diferiu significativamente das combinações com arisco + esterco $40 \%$ + húmus $20 \%$ + vermiculita $40 \%$ e arisco + esterco $40 \%$ +húmus $40 \%$ + vermiculita 20\% (Tabela 2). As menores variações das combinações de substrato ocorreram na estaca mediana com folhas e apical sem folha.

Considerando o peso da matéria seca de folhas os resultados foram bem semelhantes aos encontradas para o número de folhas. A estaca mediana sem folha novamente foi a única que apre- sentou os maiores valores dentro de todas as combinações dos substratos, ao contrário do que ocorreu para estaca apical sem folha (Tabela 3). Porém, considerando os valores obtidos dentro do fator estaca, pelas diferentes combinações de substratos, verificou-se que as maiores variações ocorreram nas estacas medianas. Por outro lado, na estaca apical sem folha não ocorreu nenhuma variação para a característica em questão (Tabela 3).

Para o peso de matéria seca de raiz, novamente verificou-se superioridade da estaca mediana sem folha dentro de todas as combinações, porém não diferiu muito das estacas mediana e apical com folhas (Tabela 4). Os resultados estão de acordo com Browse (1979) que relata que estacas semilenhosas possuem maiores condições de sobrevivência, apesar de serem mais suscetíveis à perda d'água quando as folhas estão presentes; além disso, elas apresentam elevadas quantidades de assimilados e, por isto, podem produzir raízes sob condições de fraca luminosidade. Ao contrário das duas últimas características avaliadas, os substratos não variaram dentro dos diferentes tipos de estacas. 
Tabela 4- Médias do peso de matéria seca (grama) de raiz em estacas de alfavaca-cravo (O. gratissimum L.), para os diferentes substratos. Pentecoste, (CE), UFC-FEVC, 1999.

\begin{tabular}{|c|c|c|c|c|c|}
\hline \multirow{3}{*}{$\begin{array}{r}\text { Substratos }{ }^{1} \\
\mathrm{~A}+\mathrm{E} 100 \%+\mathrm{H} 0 \%+\mathrm{V} 0 \%\end{array}$} & \multicolumn{5}{|c|}{ Tipos de estacas ${ }^{2}$} \\
\hline & \multirow{2}{*}{$\begin{array}{r}\text { EMCF } \\
0,056 \text { a } A\end{array}$} & \multicolumn{2}{|l|}{ EMSF } & EACF & \multirow{2}{*}{$\begin{array}{c}\text { EASF } \\
0,039 \text { a } A\end{array}$} \\
\hline & & 0,059 & $\overline{c A}$ & $0,021 \quad b \quad A$ & \\
\hline$A+E 80 \%+H 20 \%+V 0 \%$ & 0,131 a $A B$ & $0,187 a b$ & $A$ & $0,116 a b \quad A B$ & 0,053 a $B$ \\
\hline $\mathrm{A}+\mathrm{E} 60 \%+\mathrm{H} 40 \%+\mathrm{V} 0 \%$ & 0,108 a $A B$ & $0,097 \mathrm{abc}$ & c $A B$ & $0,153 a \quad A$ & 0,024 a $B$ \\
\hline$A+E 20 \%+H 80 \%+V 0 \%$ & $0,101 \mathrm{a} \quad A B$ & $0,162 a b c$ & $c A$ & $0,119 a b A$ & 0,028 a $B$ \\
\hline$A+E 60 \%+H 20 \%+V 20 \%$ & 0,136 a $A$ & $0,181 \mathrm{ab}$ & $A$ & $0,115 a b \quad A$ & 0,027 a $B$ \\
\hline$A+E 40 \%+H 40 \%+V 20 \%$ & 0,128 a $A$ & $0,171 a b$ & $A$ & 0,132 a $A$ & 0,018 a $B$ \\
\hline$A+E 0 \%+H 80 \%+V 20 \%$ & $0,094 \mathrm{a} \quad \mathrm{B}$ & $0,183 a b$ & $A$ & $0,049 a b \quad B$ & 0,074 a $B$ \\
\hline$A+E 40 \%+H 20 \%+V 40 \%$ & 0,128 a $A B$ & $0,203 a$ & $A$ & $0,079 a b \quad B$ & 0,042 a $\quad B$ \\
\hline$A+E 20 \%+H 40 \%+V 40 \%$ & 0,088 a $\quad B$ & $0,195 a$ & $A$ & $0,112 a b \quad A B$ & 0,060 a $B$ \\
\hline$A+E 0 \%+H 20 \%+V 80 \%$ & 0,071 a $A$ & $0,087 \mathrm{bc}$ & $c A$ & $0,077 \mathrm{ab} \quad \mathrm{A}$ & 0,060 a $A$ \\
\hline
\end{tabular}

1/A+E = arisco + esterco; $\mathrm{H}=$ húmus; $\mathrm{V}=$ vermiculita ${ }^{2} / \mathrm{EMCF}=$ estaca mediana com folha; $\mathrm{EMSF}=$ estaca mediana sem folha; $\mathrm{EACF}=\mathrm{estaca}$ apical com folha; EASF=estaca apical sem folha.

Médias seguidas por letras distintas minúsculas na vertical e maiúscula na horizontal, diferem entre si a 5\% de probabilidade pelo teste Tukey.

Pelo exposto, de acordo com as características avaliadas, observou-se resposta negativa da estaca apical sem folha, em comparação com os demais tipos de estacas. Este resultado diverge do encontrado por Zancan (1989) que utilizando estaca semilenhosa de ameixeira constatou elevada percentagem de enraizamento nas estacas retiradas da porção apical dos ramos.

Diante dos resultados, constatou-se neste trabalho ser possível a propagação vegetativa da alfavaca-cravo por estaquia, sendo a melhor estaca, a mediana sem folhas, de $25 \mathrm{~cm}$, plantadas em substrato que contenha arisco + esterco a $40 \%$ ou $20 \%$ acrescido de $20 \%$ ou $40 \%$ de húmus, respectivamente $\mathrm{e}$ mais $40 \%$ de vermiculita.

\section{LITERATURA CITADA}

BEZERRA, J.E.F.; LEDDERMAN, I.E. Propagação vegetativa por estaquia da aceroleira. In: São José, A.R.; Alves, R.E. Acerola no Brasil, produção e mercado. Vitória da Conquista: UESB, 1995 p.32-40.

BROWSE, P.M. A propagação das plantas. Lisboa: Europa - América, 1979, 228 p.

CORRÊA JÚNIOR, C.; MING, L.C.; SCHEFFER, M.C. Cultivo de Plantas Medicinais, Condimentares e Aromáticas, Jaboticabal-SP, 1994, $151 \mathrm{p}$.

COUVILLON, G.A. Rooting response to different treaments. Acta Horticulturae, v.227, p.187-196, 1988. HARTMANN, H.T.; KESTER, D.E.; DAVIES JR., F.T. Source selection and management in vegetative propagation. In:____ Plant propagation: principles and practices. 5ed. New Jersey: Prentice - Hall, 1990. Cap.8, p.165-198.

Matos, F.J.A. Farmácias vivas. $3^{\mathrm{a}}$ edição revisada e atualizada. Fortaleza: EUFC. 1998.
MENDONCA, M.C.S. Efeito do ácido indolbutírico no enraizamento de estacas de alecrim-pimenta (Lippia sidoides Cham.). (Tese mestrado), UFC, Fortaleza-CE, 1997, p.43.

MORALES, G.C.F. Influência do AIB e da presença de folhas no enraizamento de estacas de laranjeira "Valência" e tangerineiras "Montenegrinas". Porto Alegre: Faculdade de Agronomia, UFRGS, (Tese mestrado), 1990.

POKORNY, F.A.; AUSTIN, M.E. Propagation of blueberry softwood terminal cuttings in pine bark and peat media. Hortscience, St. Joseph, v.17, p.640-642, 1982.

ZANCAN, C. 1989. Influência dos fatores ambientais, fisiológicos e genéticos no pegamento $e$ desenvolvimento de microenxertos in vitro de ameixeira (Prunus salicina Lindl.). Pelotas, Faculdade de Agronomia Eliseu Maciel, UFPel, 92p. (Tese mestrado) 